\title{
A technical evaluation of wind-hydrogen (WH) demonstration projects in Europe.
}

\author{
VALVERDE, L., ALI, D., ABDEL-WAHAB, M., GUERRA, J. and HOGG, D.F.
}

(C) 2013 IEEE. Personal use of this material is permitted. Permission from IEEE must be obtained for all other uses, in any current or future media, including reprinting/republishing this material for advertising or promotional purposes, creating new collective works, for resale or redistribution to servers or lists, or reuse of any copyrighted component of this work in other works. 


\section{A technical evaluation of Wind-Hydrogen (WH) demonstration projects in Europe}

\author{
L. Valverde \\ School of Engineering, \\ University of Seville \\ Seville, Spain \\ lvalverde@etsi.us.es
}

\author{
D. Ali \\ School of Engineering, \\ Robert Gordon \\ University \\ Aberdeen, Scotland, UK \\ d.ali@rgu.ac.uk
}

\author{
M. Abdel-Wahab \\ School of the Built \\ Environment, Heriot- \\ Watt University \\ Edinburgh, Scotland, \\ UK \\ m.abdel- \\ wahab@hw.ac.uk
}

\author{
J. Guerra \\ School of Engineering, \\ University of Seville \\ Seville, Spain \\ jjguerra@us.es
}

\author{
D.F. Hogg \\ The Hydrogen Office \\ Ltd \\ Scotland, UK \\ David.Hogg@thehydrog \\ enoffice.com
}

\begin{abstract}
Investment in Renewable Energy Sources (RES) is at the center of energy policy in Europe. A key shortcoming of renewable energy is the issue of intermittency which can pose a risk to the security of energy supply. Energy storage thus becomes essential in order to address the mismatch between energy demand and supply. The utilization of Wind-Hydrogen (WH) energy storage systems and Fuel Cells provides a viable solution. This paper presents a technical evaluation of Wind Hydrogen (WH) Demonstration projects in Europe; the scope of evaluation includes a comparative analysis of: design criteria, operation and energy management together with technical challenges. It is argued that Renewable Hydrogen and Fuel cell Energy systems require more efficient electrolyzers and better energy management systems and that lab-scale testing is essential in order to inform the development of future demonstration projects.
\end{abstract}

Keywords-renewable; hydogen energy technology; wind energy demonstration projects; electrolysis, fuel cell; performance

\section{INTRODUCTION}

The energy industry is facing a transitional period. Traditional coal-fired power plants are being phased-out in some countries due to environmental regulations, such as the Directive 2008/50/EC on ambient air quality in Europe or the National Ambient Air Quality Standards in United States [1]. Such regulations are driving investment towards Renewable Energy Sources (RES), distributed generation and MicroGrids. The European Union (EU) has thus set out three specific objectives: security in the energy supply, the reduction of emissions and providing the renewable industry with competitive support [2]. The directive 2009/28/EC promotes and supports the use of RES in Europe. As a result, the EU countries have adopted policies to support the use of RES which is evident by the increase of uptake of renewable energy since 2004 (Figure 1). The share of energy from renewable sources in gross final energy consumption in the
EU-27 reached $12.5 \%$ in 2010 and is showing steady progress towards the Europe 2020 target $(20 \%)^{1}$ while the Scottish government has set a target of generating the equivalent to $100 \%$ of electricity demand from renewable sources by 2020 .

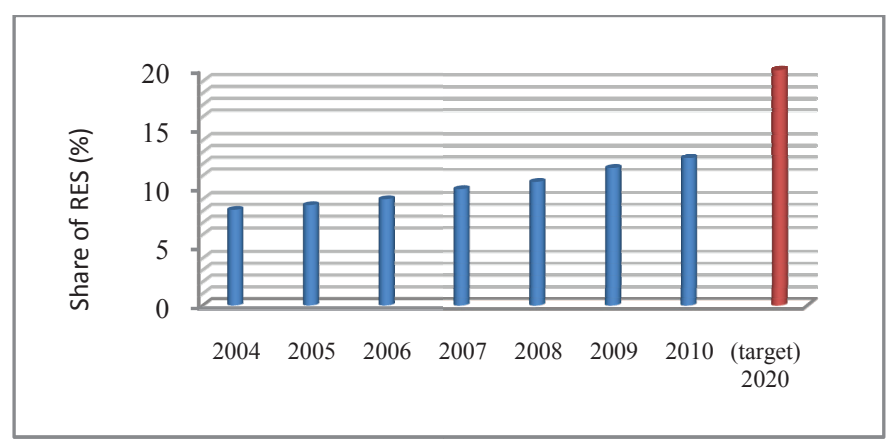

Figure. 1. Share of RES as a proportion of total energy consumption (EU-27 according to Directive 2009/28/EC). Source: Eurostat

According to Eurostat, wind generation is the most prominent RES which has doubled over the period 2005-2010 (11-22\%) the share within RES when compared to the share of wood \& biomass which has the lower increment. However, the widespread uptake of renewable energy [3] brings two main challenges. The intermittent nature of renewable energy presents a challenge for maintaining security of energy supply in order to meet variable user demand ${ }^{2}$. In addition, the massive introduction of renewable energy into the electrical grid can lead to instability in the operation of electric power systems, which may result in disconnections of the wind farms [4]. Scotland's biggest energy firms have been paid $£ 12$ million

\footnotetext{
${ }^{1}$ Source: Eurostat. Environment and Energy Analysis of the latest data on energy from renewable sources

2 Recently, the European Commission has invested $£ 2.3 \mathrm{~m}$ in pan-European Project (which includes Scotland, Italy and Portugal) which aims to explore ways for matching energy supply and demand in order to create an efficient energy system. Source: www.bbc.co.uk/news/uk-scotland-north-eastorkney-shetland-20556034
} 
to shut down their turbines when the weather was too windy ${ }^{3}$. These payments were referred to as "constraint payments" from the National Grid. A similar scenario of high wind and low demand also happened in Hamburg last August when the voltage weakened for just milliseconds causing major damage on large industrial firms ${ }^{4}$. Thus, energy storage that can absorb such excess presents a plausible means for stabilizing the grid [5].

In addition to the conventional energy storage systems (pumped hydropower, compressed air, batteries, etc..), energy storage systems that employ hydrogen $(\mathrm{H} 2)$ production through electrolysis using the surplus in renewable production and the subsequent use of this $\mathrm{H} 2$ into fuel cells offers a viable alternative for storing large amounts of energy, since hydrogen has very high energy density and can be stored with minimal energy losses over long periods [6].

The chemical properties of hydrogen make it an attractive energy carrier and an appropriate solution for the energy storage issue. Hydrogen produced, using the surplus energy from renewable sources can be stored in pressurized containers for long periods without large energy losses. When there is low or no renewable energy, $\mathrm{H} 2$ can be used in a fuel cell to produce electricity. Moreover, a major advantage of $\mathrm{H} 2$ is its added value as a chemical for the industry (from chemical and refining to metallurgical, glass and electronics [7]). Hydrogen, as an energy carrier, can be used in transport, heating, portable applications or in many stationary applications. Figure 2 shows the principle of operation of such systems.

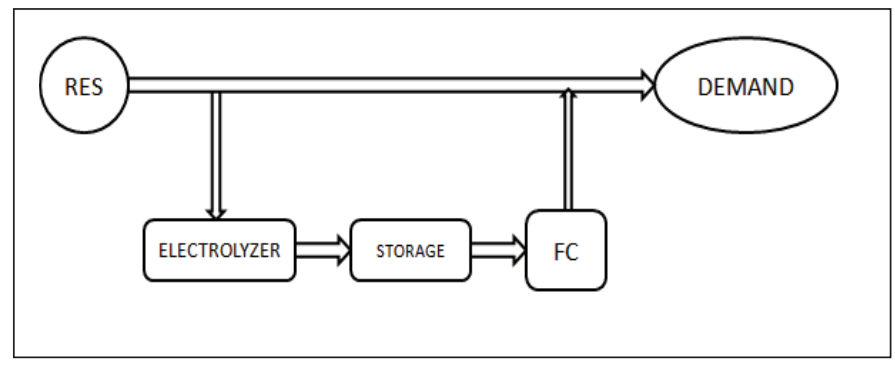

Figure 2 Layout of a Renewable Hydrogen Energy System

One key stationary application of Renewable hydrogenbased energy systems is within the built environment [8]. Nowadays, building infrastructure includes renewable energy generation to supply part of the building energy demand. The use of hydrogen technology can help reducing the carbon footprint by allowing higher penetration for RES within the built environment. However, R\&D is required in order to present a commercially viable application of hydrogen in the Built Environment which should involve the collaboration of various stakeholders (such as industry, universities and government agencies). Hydrogen technology R\&D can include computer simulations [9], lab-scale testing [10] [11] which has

\footnotetext{
${ }^{3}$ Source: www.dailyrecord.co.uk/news/business-consumer/national-gridpay-scottish-power-1468900

${ }^{4}$ http://www.spiegel.de/international/germany/instability-in-power-gridcomes-at-high-cost-for-german-industry-a-850419.html
}

the potential to inform the development of 'real world' demonstrations projects and in turn supporting the technology uptake in the built environment.

The aim of this paper is to provide an evaluation of Hydrogen based energy systems that employ renewable energy. The focus will be on the WH demonstration projects in Europe. The evaluation will include: the design criteria, operation and energy management, efficiency and performance, and technical challenges. These issues provide a common framework for understanding the variability of the systems set-up at demonstration projects.

\section{AN OVERVIEW OF WIND-HYDROGEN (WH) DEMONSTRATION PROJECTS}

In this section, a literature review on hydrogen-based energy systems has been carried out to determine their current status A number of projects have been developed in the last decade with the major goal of demonstrating the possibility of integration of RES with hydrogen storage systems. Currently there are four EU countries that have reported operational results of hydrogen-based energy systems: Spain, UK, Greece and Norway. Additionally, other leading countries like USA, Germany and Italy have developed research-oriented laboratories in order to investigate ways of improving such systems. Spain, UK, Greece and Norway have shown specific interest in this technology not only because of their good renewable energy resources but also because they have an electrical grid with low capacity for interconnection with other countries [12]. Table I shows a summary of WH demonstration projects considered in this paper. A detailed component description can be found in [13] [14].

While such demonstration projects have been installed, universities and research centers have been investigating at a lab-scale how to improve the energy captured from wind, the equipment efficiency and the energy management [11] [15]. WH research laboratories have been established worldwide with a view of understanding how the technology would work in a controlled lab-environment as opposed to an actual building context. As such, lab-scale application can inform the development of demonstration projects. For example, in Norway (table 1), the collaboration between the Norwegian Institute for Energy Technology (IFE) and the hydrogen standalone power laboratory (HSAPS) has allowed the development of the Utsira project with a solid background and guidelines from the laboratory experience.

TABLE I. EUROPEAN WIND-HydRogEN DEMONSTRATION PROJECTS CONSIDERED

\begin{tabular}{|c|c|c|c|c|c|}
\hline $\begin{array}{c}\text { Project } \\
\text { Name }\end{array}$ & Year & Country & $W T^{\boldsymbol{a}}(\boldsymbol{k W})$ & $\boldsymbol{E L}^{\boldsymbol{b}}(\boldsymbol{k W})$ & $\boldsymbol{F C} / \mathbf{I C E}(\mathbf{k W})$ \\
\hline Utsira & $\mathbf{2 0 0 4}$ & Norway & $\mathbf{1 2 0 0}$ & $\mathbf{5 0}$ & $\mathbf{6 5}$ \\
\hline Hari & 2004 & UK & 30 & 34 & 7 \\
\hline Ither & $\mathbf{2 0 0 5}$ & Spain & $\mathbf{6 3 5}$ & $\mathbf{7 0}$ & $\mathbf{1 , 2}$ \\
\hline Res2H2 & 2005 & Greece & 500 & 25 & - \\
\hline
\end{tabular}




\begin{tabular}{|c|c|c|c|c|c|}
\hline $\begin{array}{c}\text { Project } \\
\text { Name }\end{array}$ & Year & Country & $\boldsymbol{W T}^{\boldsymbol{a}}(\boldsymbol{k W})$ & $\boldsymbol{E L}^{\boldsymbol{b}}(\boldsymbol{k W})$ & $\boldsymbol{F C}^{\boldsymbol{c}}$ /ICE(kW) \\
\hline Pure & $\mathbf{2 0 0 5}$ & UK & $\mathbf{3 0}$ & $\mathbf{1 7 , 5}$ & $\mathbf{5}$ \\
\hline Sotavento & 2007 & Spain & 17560 & 288 & 55 \\
\hline Res2H2 & 2007 & Spain & 225 & 50 & 30 \\
\hline Hidrolica & 2009 & Spain & 80000 & 60 & 12 \\
\hline $\begin{array}{c}\text { Hydrogen } \\
\text { Office }\end{array}$ & $\mathbf{2 0 1 0}$ & UK & $\mathbf{7 5 0}$ & $\mathbf{3 0}$ & $\mathbf{1 0}$ \\
\hline
\end{tabular}

a. WT: Wind Turbine. b. EL: Electrolyzer, c. FC: fuel cell, ICE: Internal Combustion Engine

According to the International Energy Agency (IEA) report [13], demonstration projects given in Table I have proved to be successful in terms of operation and system integration and in turn confirm the viability of using Wind Hydrogen based energy systems. However, this evaluation focused on describing the projects' background, parties involved and overall experiences, rather than detailed performance analysis [13]. Therefore, this paper attempts to address this gap with an emphasis on the Hydrogen Office (HO) demonstration project as a case study in this paper.

The Hydrogen Office project demonstrates the role that energy efficiency, renewables and hydrogen can play in energy security and in reducing the future impact of climate change. The Hydrogen Office is operated by Bright Green Hydrogen, a not-for-profit private company, whose aim is to increase awareness and understanding of hydrogen and other renewable technologies within Scotland. The building is powered by a novel renewable hydrogen energy system, using wind energy directly when available, while storing surplus energy as hydrogen for a proportion of the building's needs during periods when wind is unable to meet demand. The energy system layout is shown in Figure 3. A more detailed component description is provided below:

- A $750 \mathrm{~kW}$ wind turbine, manufactured by Global wind Power designed by Norwin with an ASR (Active stall regulation).

- A $30 \mathrm{~kW}$ alkaline electrolyzer manufactured by ERRE DUE, with a nominal hydrogen production of 5.33 $\mathrm{Nm}^{3} / \mathrm{h}$ and an oxygen production of $2.6 \mathrm{Nm}^{3} / \mathrm{h}$. The outlet hydrogen pressure is 12 barg. The hydrogen reaches a purity of $99.3-99.8 \%$. An associated purifier increases hydrogen purity to $99.995 \%$

- A storage tank where hydrogen is stored without further compression. The maximum tank filling pressure is 12 barg (which is the electrolyzer delivering pressure). The total tank storing capacity is $11 \mathrm{~kg}$ of hydrogen.

- A $10 \mathrm{~kW}$ PEM fuel cell system manufactured by Altergy Systems, composed of two $5 \mathrm{~kW}$ stacks. The fuel cells are auto-humidified and take the oxygen from the air. A battery bank provides power during the fuel cell start-up.

- Electric vehicle powered by lead-acid batteries that are charged either by the wind turbine or by the fuel cell.

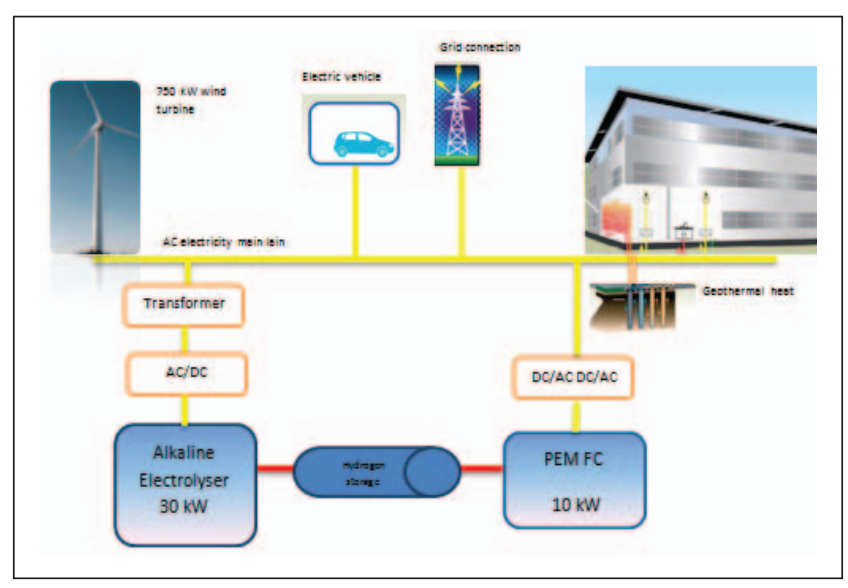

Figure 3. Layout of the $\mathrm{H} 2$ Office System comprising a $750 \mathrm{~kW}$ wind turbine, $30 \mathrm{~kW}$ alkaline electrolyzer, $120 \mathrm{Nm} 3$ pressurized tank, $10 \mathrm{~kW}$ PEM fuel cell and electric vehicle

The power produced by the wind turbine feeds most of the building's demand. When there is a surplus of power, an alkaline electrolyzer is used to split the water into hydrogen and oxygen. The hydrogen is stored in a stainless steel tank until periods of low wind. During these periods, the fuel cell consumes the hydrogen, producing electricity to power the offices in the building. Thus, the plant scheme is comparable to the generic system diagram shown in Figure 3.

Due to the constraint of data availability, the performance and efficiency comparison will focus only on four projects namely: Utsira, ITHER, PURE and the Hydrogen Office. The comparative analysis will include design criteria, energy management, efficiency, performance and technical challenges - which are subsequently discussed.

\section{EVALUATION OF WH DEMONSTRATION PROJECTS}

\section{A. Comparison Framework}

\section{1) Design Criteria}

The system design criterion is a function of the project's location, weather conditions, user demand, scale, whether it is isolated or grid-connected, etc. However, there are some common criteria followed in the design stage for such demonstrations projects, the most common ones are:

- To supply user demands.

- To achieve energy balance in the autonomous system.

- To design the peak power capability in relation to maximum expected customer load.

- $\quad$ To meet the power quality requirements.

- Meet redundancy and emergency mode requirements.

- Review the state of the art of hydrogen technologies. 
- Robustness and reliability.

Beyond these common and generic design criteria, some differentiations can be found for each demonstration project:

The operation of a wind turbine at a constant speed as opposed to a variable speed is found to be a debatable area in literature. A study demonstrates that variable speed operation (as this in Utsira, ITHER and HARI) can provide considerable power smoothing, acting as a low pass filter [16] whereas most of the projects have installed constant-speed wind turbines.

In the PURE project [17], which includes a heating system, the best utilization of the wind turbine power has been found to exist when the wind turbines are directly connected to the electric heating system to warm up the buildings. The reason behind this is the direct correlation between high wind speeds and the need for increased heating energy.

The overall design of the Utsira concept [18] has been developed through detailed simulations that use historical wind data to simulate expected energy production from wind along with domestic load measurements from the island. A hydrogen combustion engine has been installed in order to complete the project within the project's schedule and to add robustness.

The HARI project also relied on modeling to perform the system design. As with most of the projects, the system has been designed to ensure robustness and reliability rather than component and system efficiency. What differentiates this project is that the system integrates a variety of renewable sources. This project was conceived as a mixed facility between a demonstration project and a testing laboratory.

Laboratory testing is a resource not commonly used in the projects. In the lab, specific tests emulating the real conditions can be performed in a controlled environment. The tests also aim to evaluate the system performance data that the manufacturers claim. Flexibility of laboratories allows for a better understanding and operation of the equipment.

The optimum sizing of the electrolyzer, the fuel cell and the energy storage relative to the wind turbine size is a complex function of site meteorology (e.g. annual mean wind speed), capital costs, required gas quality, and the local market for electricity [16]. Plant power reports confirm that most of the demonstration plants components are often not ideally sized due to cost constraints or the lack of specific equipment sizes in the market. Nonetheless, modeling-based studies were carried out in the context of these projects to highlight the importance of optimal sizing in the hydrogen systems [6], [19], [20].

\section{2) Operation and energy management}

This section analyses WH plant operation in terms of energy management. The energy management implemented in these projects has been classified within this paper into three categories:

\section{- Heuristic energy management strategy 1 (HEM1)}

This is a simple strategy that is typical for large power plants without short-term energy storage. The electrolyzer is switched on when the average net power is positive for a certain time span. Analogously, the back-up sources (FC, etc.) are activated when the RES power is under a certain level for a pre-defined time span. This energy management strategy is the one implemented in all the given demonstration projects, with the exception of HARI project.

\section{- Heuristic energy management strategy 2 (HEM2)}

This strategy is based on the battery state of charge (SOC). Thus, it is found in power plants that include batteries as short-term energy storage devices. The principle of operation uses the hydrogen path when a high energy mismatch occurs in the system. In other words, the electrolyzer is activated when the battery $\mathrm{SOC}$ is high and the fuel cell is activated when the SOC is very low. The switch off of both devices (electrolyzer and fuel cell) is defined by a hysteresis band [21]. This is the energy management strategy implemented in the HARI project and in many hydrogen laboratories, such as: HYLAB, HSAPS among others.

Within these two strategies, individual equipment such as the electrolyzer and the fuel cell, can operate in two basic different operation modes: fixed power and variable power. Fixed power is common for the electrolyzer, due to the constraints in variable operation for alkaline electrolyzers.

- Advanced control strategies for Energy Management (EM3)

This comprises more complex algorithms and on-line optimal set-point calculations. Recent work in this field has reported new control strategies on power management that could be useful for hydrogen storage [22]. Nonetheless, the major drawback is this field is that it is still far from experimental validation. To the authors' knowledge, the unique lab that is working on experimental validation of advanced control strategies is HYLAB in Seville, Spain [23].

\section{3) Efficiency and performance}

The turnaround energy efficiency when using hydrogen path will lose some of the surplus energy.

The demonstration projects in Table I reported efficiencies for the electrolyzer of around 40-55\% (HHV at NPT) [20], [24], [14]. These values include the Balance of Plant (BoP). Without BoP, the efficiency reported is around 65-75\% [17], [24]. The fuel cells reported efficiencies are between 40-45\% (H2 input to electrons output are based on LHV of H2) [14], [24]. However, some projects use a hydrogen internal combustion engine (Utsira, Prince Edward Island, Sotavento, Ramea Island), whose efficiency is very low, between 17-18\% [25]. Thus, other projects avoid the use of combustion engines or use them only for emergency back-up. Additionally, projects with pressurized tanks spend between $5-10 \%$ of the hydrogen energy (HHV) in the compression. This loss is not reported for projects using metal hydride storage systems, ITHER, RES2H2 
(Greece). The systems power electronics increases losses further. Typical values of efficiency are 90-95\% [18], [24]. However, some projects [20] reported $75-85 \%$ efficiency in the power converters. Overall, the hydrogen roundtrip path, has an average efficiency of $15-25 \%$. These values can be improved to $45-50 \%$ by using Combined Heat and Power (CHP) and thermally coupled metal-hydride electrolyzer system [13]. However, the effort put into those demonstration projects has not focused on the efficiency as much as it did on the reliability. It should be noted that, an efficiency of $25 \%$ does not mean a $75 \%$ of energy loss but means a $25 \%$ of energy increase as this energy that would otherwise have been wasted, is stored and used at times when demand exceeds supply.

The demonstration projects highlighted the importance of operating the electrolyzer/fuel cell at nominal temperatures to improve the efficiency. However, the experience shows that nominal temperature conditions cannot be always reached.

In order to perform a quantitative technical evaluation of WH demonstration projects, a list of performance indicators has been identified. Table II presents the available data for performance indicators aforementioned. This benchmarking has been limited to the most similar plants among the demonstration projects in size, topology and energy management: Utsira, ITHER, PURE and the Hydrogen Office.

TABLE II. PERFORMANCE COMPARISON

\begin{tabular}{|c|c|c|c|c|}
\hline Project $^{a}$ & \multirow{2}{*}{ Utsira } & \multirow{2}{*}{ ITHER } & \multirow{2}{*}{ PURE } & \multirow{2}{*}{ HO } \\
\hline Indicator & & & & \\
\hline WT(MWh) & $\mathrm{n} / \mathrm{a}$ & 694.5 & 20 & 1204,5 \\
\hline $\mathrm{WS}(\mathrm{m} / \mathrm{s})$ & $>10$ & 4,2 & 8 & 4,7 \\
\hline WT(kW) & 53 & 79,28 & $\mathrm{n} / \mathrm{a}$ & 84,15 \\
\hline EZ time (h) & 1500 & 1000 & 250 & 690 \\
\hline $\begin{array}{l}\mathrm{FC} / \mathrm{H} 2_{\text {engine }} \\
\text { (h) }\end{array}$ & 500 & $\mathrm{n} / \mathrm{a}$ & 150 & 1070 \\
\hline EZ on-off & $200-300$ & 100 & 200 & 624 \\
\hline FC on-off & $200-300$ & $\mathrm{n} / \mathrm{a}$ & $\mathrm{n} / \mathrm{a}$ & 370 \\
\hline $\begin{array}{l}\text { System } \\
\text { availability } \\
\text { (\%) }\end{array}$ & 89 & 90 & $80-85$ & $80-90$ \\
\hline
\end{tabular}

a. Sample periods: Utsira( 2004/2005), ITHER( 2005/2006), PURE (2005/2006), HO (Nov-2011/Oct-

Below are the definitions of the aforementioned indicators:

WT: Wind Turbine (WT) average annual production (MWh): This indicator identifies the quality of the WT performance and also whether the location has been chosen correctly.

WS: Average wind speed $(\mathrm{m} / \mathrm{s})$ : This indicator helps to identify if the problem comes from the WT or from the location choosing.

WT average power output $(\boldsymbol{k W})$ : This value shows the optimal working point of the wind turbine.

Electrolyzer annual operating time (hours): This value indicates the electrolyzer usage.
FC annual operating time (hours): The use of the fuel cell in the plant indicates the time when the demand is higher than the renewable power production.

Total number of start-stop events: The number of electrolyzer and fuel cell switch on and off can dramatically influence the equipment lifetime [20]. A good control strategy should minimize the number of start-stop [21]. In contrast a bad control strategy doesn't take this into account, incurring in a high number of start-stop events.

System availability (\% total time): This parameter gives the percentage of total operating time that the system has been working. Thus, it is a reliability indicator.

The analysis of the key indicators has showed the following: The wind speed is not particularly high for ITHER and HO project. The energy production of the Hydrogen Office WT indicates that it has been oversized. The electrolyzer annual operating time is low for the PURE project and the Hydrogen Office compared to Utsira and ITHER. The reason is primarily due to the low demand on H2. Thus, the HO hydrogen tank is normally full and the electrolyzer is not switched on. The fuel cell from the Hydrogen Office shows a more intensive use (double than Utsira). Taking into account the relative low average wind speed at the Hydrogen Office, it is reasonable that the fuel cell was working frequently. The start-stop of the electrolyzer and the fuel cell for the Hydrogen Office are comparatively high with the other projects. This indicates more variability in the wind speed.

\section{4) Technical Challenges}

This section looks into system failures, technical issues encountered and major overhaul.

Regarding the wind turbine, most projects used commercial and well known turbines without any technical challenge. More challenging prototype turbines have been tested in the PURE project where strong winds were faced with new advanced prototypes. After a difficult initial stage, successful operation was achieved.

The problems encountered with alkaline electrolyzers are: the necessity of operation between $20-100 \%$ of power rating to avoid gas impurities. Stack degradation has been observed in many projects [20], [16] under variable operation conditions. The power electronics associated may cause over-harmonics. The possible impurities inside the sealed water tank should be taken into account as they can damage the electrolyzer stack.

The PEM fuel cell demonstrated few technical problems. The most important has been reported by Utsira project: there has been an incident where glycol-cooling liquid leaked and damaged several cells. Frequent malfunction in the alarm system and power electronics caused shut-downs. Moreover, the main problem reported is the stack degradation with or without operation.

Harmonics and electricity quality problems have been reported to be from the power electronics on DC coupled systems; however the technology is improving day by day. Looking into more modern systems, the trend of the technology appears to be AC coupled compared to those designed/installed 10 years ago and earlier. The electricity in that case can be 
transformed up or down the voltage ladder with relative ease compared with DC, thus avoiding many of the old problems. Also a strong technical reason to migrate to $\mathrm{AC}$ is usually the cost savings of using higher voltage $\mathrm{AC}$, instead of lower voltage, higher amperage DC. The transmission losses are also lower with $\mathrm{AC}$ due to the lower current. It is also easier to expand an AC system over a DC system, as a DC system usually requires some form of battery connected directly to a common rail DC bus. Any increase in the load or generation leads to a consequent increase in the battery since its charge/discharge rate is a function of its ampere hour capacity. With an AC coupled system more generation and/or load will synchronize as part of an 'infinite bus' approach. Conversion from AC to DC for electrolysis is usually achieved through the use of modern microprocessor controlled silicone controlled rectifiers (SCR) that are very efficient (usually better than 93\%) and are very reliable.

\section{B. Common key lessons learned}

The common key lessons learned are:

- Serious consideration of the electrical loop quality for consumer demand (to avoid voltage, frequency and harmonics issues).

- Careful consideration of static and dynamic performance is required. Systems designed using steady-state models can lead to overestimating the hydrogen production [15].

- Accurate simulations cannot be performed due to the lack of equipment data and detailed process knowledge.

- The importance of choosing equipment with a high degree of fail-safe and remote operation [18].

- Optimal sizing has not been applied due to the lack of the exact equipment size in the market [17].

- Equipment characterization (operational curves) and testing the subsystems separately (electrolyzer, wind turbine, fuel cell) are strongly recommend for the success of such projects.

- The redundancy monitoring has been highlighted as a very important issue to ensure the system safety and reliability.

- A battery bank is recommended for smooth electrolyzer operation in DC coupled systems. The experience gained from these projects indicates that the lifetime of the electrolyzer as well as the fuel cell could be severely limited by the frequent start/stop cycles.

- The alkaline electrolyzer is not effective for intermittent operation.

- Thermal insulation could play an important role in improving the efficiency. The better the insulation, the faster the optimum temperature is reached.
- The non-optimal equipment sizing causes inefficient operation, for example: a small size of hydrogen storage relative to the electrolyzer size leads to a waste in the surplus energy produced.

- Voltage instability can occur and must be considered. Power electronics should be designed to handle voltage and frequency variations, resonance and also reactive power.

\section{CONCLUSIONS AND FUTURE WORK}

In this paper a technical evaluation of wind-hydrogen demonstration projects in Europe has been discussed. A number of key lessons learned during the plants' design and operation have been compiled to allow an analysis of the main achievements and challenges of the technology. Analysis of the operational data confirms that more efficient electrolyzers are needed [13]. CHP units are strongly recommended to be integrated in future systems to allow higher efficiency. The energy management control is a field with a great margin of improvement. The technical issues encountered are possibly related to the early technology stage in some cases and to the energy management simplicity in other cases. Thus, improved energy management can help in avoiding the issues encountered with the electrolyzer and fuel cell operation. The Lab-scale implementation could help to undertake some of the technical challenges aforementioned with lower cost than realscale.

In conclusion, the considered projects demonstrate the possibility of integrating the wind energy with hydrogen to partially cover the intermittency of the wind. The evaluation shows how the technology has been developed during the last decade to bridge the gap between the reliability of equipment operation and meeting the real end-user requirements. Expanding the development demonstration projects can support successful application in buildings particularly for remote locations which has the potential for being connected in a microgrid. Meanwhile, the market barriers should be reduced, using feed-in-tariffs for example, and educational work to increase public awareness of WH demonstration projects. Indeed an in-depth understanding of demonstration projects could support the future development and deployment of wind-based hydrogen systems.

\section{ACKNOWLEDGMENT}

We are grateful to the Hydrogen Office for providing information and access to their facilities.

\section{REFERENCES}

[1] C. Van Atten, A. Saha, L. Reynolds, "Benchmarking air emissions of the 100 largest power producers in the United States," M.J. Bradley \& Associates, LLC, 2012.

[2] Final Report Of The High Level Group for Hydrogen and Fuel Cells, "Hydrogen Energy and Fuel Cells Technologies: A vision of our future," Brussels, 2003. 
[3] European Wind Energy Association, Green Growth - The impact of wind energy jobs and the economy, 2012

[4] E.Centeno, T.Ackermann, "Grid Issues for Electricity Production Based on Renewable Energy Sources in Spain Portugal, Germany, and United Kingdom," Stockholm , 2008

[5] F. Santjer, G. J. Gerdes, "Wind Turbine Grid Connection and Interaction," Deutsches Windenergie-Institut, Wilhelmshaven, 2001

[6] D. Ali, "Energy capacity and economic viability assessment of the renewable hydrogen energy storage as a balancing mechanism in addressing the electric system integration issues inherent with variable renewable energy resources," in roceeding of the IET Reliability of Transmission Distribution Networks Conference RTDN, London, 2011

[7] R. Ramachandran, R. K. Menon. "An overview of industrial uses of hydrogen", International Journal of Hydrogen Energy, Vol. 23, Issue 7, pp. 593-598, 1998.

[8] M Abdel-Wahab, D. Ali, , "A conceptual framework for the evaluation of Fuel-Cell (FC) energy systems in the Built Environment," International Journal of Green energy, 2010.

[9] T. Zhou, B. Francois, "Modeling and control design of hydrogen production process for an active hydrogen/wind hybrid power system," International Journal of Hydrogen Energy, pp. 21-30, 2009.

[10] K. Agbossou, M. Kolhe , J. Hamelin, TK. Bose, "Performance of a stand-alone renewable energy system based on energy storage as hydrogen," IEEE T Energy Conversion, 19, 2004

[11] L. Valverde, F. Rosa, C. Bordons, "Design, planning and management of a hydrogen-based microgrid," IEEE Transactions on Industrial Informatics, Issue 99, 2013.

[12] WWEA, World Wind Energy Association, "World Wind Energy Report," Bonn, 2010.

[13] Ø. Ulleberg et al., "IEA agreement on the Production and Utilization of Hydrogen," 2009.

[14] Red Electrica de España y grupo Joly, "Situación y retos de las energías renovables," 2012.

[15] F.J. Pino, "Análisis de Sistemas Integrados de Producción de Hidrógeno a partir de Energía Eólica. Aportaciones al modelado dinámico de sistemas.," Sevilla, 2010.

[16] A.G. Dutton et al. "Experience in the design, sizing, economics, and implementation of autonomous wind-powered hydrogen production systems," International Journal of Hydrogen Energy, pp. 705-722, 2000

[17] R. Gazey, S.K. Salman, D.D. Aklil-D’Halluin, "A field application experience of integrating hydrogen technology with wind power in a remote island location," Journal of Power Sources, pp. 841-847, 2006.

[18] Ø. Ulleberg, T. Nakken,A. Ete, "The wind/hydrogen demonstration system at Utsira in Norway: Evaluation of system performance using operational data and updated hydrogen energy system modeling tools," International Journal of Hydrogen Energy", 35, pp. 1841 -1852, 2010.

[19] R. Gazey, D. Ali, D. Aklil, "Techno-Economic Assessment of Hydrogen Energy Storage Systems for Enabling the Projected Increase of Renewables onto Electrical Power Grids," in Proceeding of the IET Renewable Power Generation Conference RPG, Edinburgh, 2011

[20] M. Little, M. Thomson, D. Infield, "Electrical integration of renewable energy into stand-alone power supplies incorporanting hydrogen storage," International Journal of Hydrogen Energy 32, pp. 1582-1588, 2007.

[21] D. Ipsakis et al. "The effect of the hysteresis band on power management strategies in a stand-alone power system," Energy 33 , pp. 1537-1550, 2008.

[22] E.M. Stewart, A. Lutz, S. Schoenung, , "Modeling, analysis and control system development for the italian hydrogen house",International Journal of Hydrogen Energy, Vol. 34, Issue 4, pp. 1638-1646, 2009.
[23] L. Valverde, C. Bordons, F. Rosa "Power Management using Model Predictive Control in a hydrogen-based microgrid," in IECON, Montreal, 2012

[24] Ø. Ulleberg et al. , "Hydrogen Demonstration Project Evaluations," 2007

[25] T. Nakkena, E. Frantzenb, E. F. Hagenc, H. Strømd, "Utsira demonstrating the renewable hydrogen society," in World Hydrogen Energy Conference, Lyon, 2006

[26] F. J. Pino, L. Valverde, F. Rosa, "Influence of wind turbine power curve and electrolyzer operating temperature on hydrogen production in windhydrogen systems," Journal of Power Sources 196 , pp. 4418-4426, 2011 